\title{
Nitric Oxide Regulates Plant Growth, Physiology, Antioxidant Defense, and Ion Homeostasis to Confer Salt Tolerance in the Mangrove Species, Kandelia obovata
}

\author{
Mirza Hasanuzzaman ${ }^{1,2, *(D)}$, Masashi Inafuku ${ }^{1}$, Kamrun Nahar ${ }^{3}$, Masayuki Fujita ${ }^{4}$ and Hirosuke Oku ${ }^{1, *}$ \\ 1 Molecular Biotechnology Group, Center of Molecular Biosciences (COMB), Tropical Biosphere Research \\ Center, University of the Ryukyus, 1 Senbaru, Nishihara, Okinawa 903-0213, Japan; \\ h098648@eve.u-ryukyu.ac.jp \\ 2 Department of Agronomy, Faculty of Agriculture, Sher-e-Bangla Agricultural University, \\ Dhaka 1207, Bangladesh \\ 3 Department of Agricultural Botany, Faculty of Agriculture, Sher-e-Bangla Agricultural University, \\ Dhaka 1207, Bangladesh; knahar84@yahoo.com \\ 4 Laboratory of Plant Stress Responses, Department of Applied Biological Science, Faculty of Agriculture, \\ Kagawa University, 2393 Ikenobe, Miki-cho, Kita-gun, Kagawa 761-0795, Japan; fujita@ag.kagawa-u.ac.jp \\ * Correspondence: mhzsauag@yahoo.com (M.H.); okuhiros@comb.u-ryukyu.ac.jp (H.O.)
}

check for updates

Citation: Hasanuzzaman, M.; Inafuku, M.; Nahar, K.; Fujita, M.; Oku, H. Nitric Oxide Regulates Plant Growth, Physiology, Antioxidant Defense, and Ion Homeostasis to Confer Salt Tolerance in the Mangrove Species, Kandelia obovata. Antioxidants 2021, 10, 611. https:// doi.org/10.3390/antiox10040611

Academic Editor: Luca Sebastiani

Received: 3 March 2021

Accepted: 12 April 2021

Published: 16 April 2021

Publisher's Note: MDPI stays neutral with regard to jurisdictional claims in published maps and institutional affiliations.

Copyright: (c) 2021 by the authors. Licensee MDPI, Basel, Switzerland. This article is an open access article distributed under the terms and conditions of the Creative Commons Attribution (CC BY) license (https:// creativecommons.org/licenses/by/ $4.0 /)$.

\begin{abstract}
Facultative halophyte Kandelia obovata plants were exposed to mild $(1.5 \% \mathrm{NaCl})$ and severe $(3 \% \mathrm{NaCl})$ salt stress with or without sodium nitroprusside (SNP; $100 \mu \mathrm{M}$; a NO donor), hemoglobin $(\mathrm{Hb}, 100 \mu \mathrm{M}$; a NO scavenger), or Nw-nitro-L-arginine methyl ester (L-NAME, $100 \mu \mathrm{M}$; a NO synthase inhibitor). The plants were significantly affected by severe salt stress. They showed decreases in seedling growth, stomatal conductance, intercellular $\mathrm{CO}_{2}$ concentration, SPAD value, photosynthetic rate, transpiration rate, water use efficiency, and disrupted antioxidant defense systems, overproduction of reactive oxygen species, and visible oxidative damage. Salt stress also induced ion toxicity and disrupted nutrient homeostasis, as indicated by elevated leaf and root $\mathrm{Na}^{+}$ contents, decreased $\mathrm{K}^{+}$contents, lower $\mathrm{K}^{+} / \mathrm{Na}^{+}$ratios, and decreased Ca contents while increasing osmolyte (proline) levels. Treatment of salt-stressed plants with SNP increased endogenous NO levels, reduced ion toxicity, and improved nutrient homeostasis while further increasing Pro levels to maintain osmotic balance. SNP treatment also improved gas exchange parameters and enhanced antioxidant enzymes' activities (catalase, ascorbate peroxidase, monodehydroascorbate reductase, and dehydroascorbate reductase). Treatment with $\mathrm{Hb}$ and L-NAME reversed these beneficial SNP effects and exacerbated salt damage, confirming that SNP promoted stress recovery and improved plant growth under salt stress.
\end{abstract}

Keywords: halophytes; antioxidants; reactive oxygen species; soil salinity; signaling molecules; abiotic stress

\section{Introduction}

Among the plethora of abiotic stresses experienced by plants, salt stress has attracted the attention of plant scientists because of its complexity and its widespread effects over different regions of the globe. The global rise of temperature is gradually increasing the sea level and threatening coastal regions with salinity problems [1,2]. Salinity causing significant challenges in the way of crop cultivation and food production for a growing global population. Salt stress induces osmotic/dehydration stress and ion toxicity that disrupts the structure and function of biomolecules, including lipids, proteins, and DNA, thereby destroying the structure of biomembranes and causing damage to cell organelles [3]. These changes adversely affect vital phenological processes and disrupt critical physiological functions, including water uptake, water use efficiency, nutrient uptake and mobilization, transpiration, respiration, photosynthesis, and assimilation of photosynthate [4-6]. 
Current strategies to address salt stress have included incorporating modern cultivation practices and the introduction of plant species that can adapt to or tolerate salt stress.

Kandelia obovata, a mangrove species widely distributed in extremely saline environments in eastern Asia [7]. Learning from such halophytes and tailoring the traits associated with high salinity tolerance may build a foundation for salt tolerance in glycophytes.

Reducing photosynthesis is one of the major consequences of salt stress. Salt stress can damage chloroplast membranes and destroy the structure of these organelles. It also reduces stomatal conductance, thereby reducing carbon dioxide uptake, decreasing the carboxylation reaction of RuBisCO, and depressing photosystem II (PSII) activity, electron transport, and photophosphorylation activity [8-10]. This salt-induced stomatal closure and inhibition of photosynthesis exposes chloroplasts to excessive excitation energy that leads to the aggravated generation of reactive oxygen species (ROS), including superoxide $\left(\mathrm{O}_{2}{ }^{\bullet-}\right)$, hydrogen peroxide $\left(\mathrm{H}_{2} \mathrm{O}_{2}\right)$, hydroxyl radical $\left(\mathrm{OH}^{\bullet}\right)$, and singlet oxygen $\left({ }^{1} \mathrm{O}_{2}\right)$ that cause serious damage to plant cells [11-13]. Plants have internal antioxidant defense systems that scavenge ROS and reduce this oxidative stress to some extent, and some plant species with highly active antioxidant systems are more tolerant of ROS and, therefore, of salt stress. Nonenzymatic antioxidants (ascorbate (AsA), glutathione (GSH), $\alpha$-tocopherol, phenolic compounds, alkaloids, and nonprotein amino acids) and antioxidant enzymes [(superoxide dismutase (SOD), catalase (CAT), ascorbate peroxidase (APX), monodehydroascorbate reductase (MDHAR), dehydroascorbate reductase (DHAR), glutathione reductase (GR), glutathione peroxidase (GPX), glutathione $S$-transferase (GST), and peroxidases (POD)] function to scavenge ROS and decrease their levels under stress conditions [13-15].

Nitric oxide (NO) has recently been recognized as a potential signaling molecule and is often termed a plant hormone [16]. Enhancement of endogenous NO levels, as well as the exogenous application of $\mathrm{NO}$, has been reported to improve salt tolerance via several different mechanisms. NO can stimulate the activity of proton pumps and the $\mathrm{Na}^{+} / \mathrm{H}^{+}$antiport in the tonoplast, thereby improving the $\mathrm{K}^{+} / \mathrm{Na}^{+}$ratio $[17,18]$. NOinduced improvement in the functioning of antioxidant systems also alleviates oxidative stress [19-21]. NO regulates the activity of phosphoenolpyruvate carboxylase kinase to mediate responses of plants to salinity [22]. NO also modulates stomatal conductance, promotes quenching of excess energy, and raises the quantum yield of PSII to improve photosynthesis [23-26].

Based on previous research, we hypothesized that NO could have a potential role in the tolerance of mangrove plants to high salinity. For this reason, we exposed mangrove plants to very high salt concentrations to understand the response and physiology behind the adaptative behavior of K. obovata growing in highly saline conditions. Our overall goal is to exploit this knowledge to instill salt tolerance in other cultivated plants that today face severe damage and crop losses due to salinity. Here, we examined mangrove plants' response to high salt stress and determined the effects of exogenously applied NO on salt tolerance in this plant.

\section{Materials and Methods}

\subsection{Growth Condition and Treatments}

Healthy propagules were collected from the Iriomote mangrove forest, Okinawa, Japan. The propagules were washed and planted in Wagner pots containing salt-free sand. The propagules were allowed to grow in a glasshouse at the University of the Ryukyus, Okinawa, Japan, under controlled environmental conditions (relative humidity $60-70 \%$, temperature $25 \pm 2{ }^{\circ} \mathrm{C}$, light $600 \mu \mathrm{mol} \mathrm{m}^{-1} \mathrm{~s}^{-1}$ and photoperiod from 12 to $14 \mathrm{~h}$ ) in stagnant water. The experiment was conducted following a completely randomized design (CRD) with three replicates. After two months, the seedlings were exposed to freshwater or to water containing two salt levels $(1.5$ and $3 \% \mathrm{NaCl})$. Each set of seedlings was treated with $100 \mu \mathrm{M}$ sodium nitroprusside (SNP, a NO donor), $100 \mu \mathrm{M}$ hemoglobin $(\mathrm{Hb}$, a NO scavenger), and $100 \mu \mathrm{m} \mathrm{N} \omega$-nitro-L-arginine methyl ester (L-NAME, a NO 
synthase inhibitor) and allowed to grow for two more months. The solutions were renewed every 15 days. At the end of the experiment, the plants were harvested and separated into shoots and roots. After washing well with distilled water, the plant parts were ground to a fine powder in liquid nitrogen and stored at $-80{ }^{\circ} \mathrm{C}$ until further use. The experiment was replicated three times.

\subsection{Quantification of Nitric Oxide}

Nitric oxide was measured indirectly by quantifying nitrite. To determine the leaves' NO contents, $0.5 \mathrm{~g}$ of freshly plucked leaves were ground in an ice-cold mortar with acetic acid buffer $(50 \mathrm{mM}, \mathrm{pH} 3.6)$ and then centrifuged $(10,000 \times g, 15 \mathrm{~min})$ to remove the residue. The supernatants were decolorized with charcoal and mixed with Griess reagent. Griess reagent was prepared with $\mathrm{N}$-1-naphthylethylenediamine dihydrochloride, sulfanilamide and phosphoric acid. The absorbance was taken at $540 \mathrm{~nm}$, and the amount of NO was calculated using a standard curve [21].

\subsection{Measurement of Gas Exchange and Photosynthetic Parameters}

Data of stomatal conductance, intercellular $\mathrm{CO}_{2}$, photosynthetic rate, transpiration rate and water use efficiency were determined using a LiCOR 6400 open system portable infrared red gas analyzer (IRGA) (LI-COR Biosciences, Lincoln, NE, USA) from fully expanded leaves at 10 a.m. to 2.00 p.m. The conditions, which were used for the equipment/leaf chamber were as follows: ambient pressure $99.2 \mathrm{kPa}$, atmospheric $\mathrm{CO}_{2}$ con-

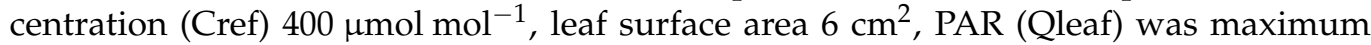
up to $900-1000 \mu \mathrm{mol} \mathrm{m}{ }^{-2} \mathrm{~s}^{-1}$ and the chamber water vapor pressure varied from 4.0 to 5.8 mbar [27]. SPAD values were recorded using a SPAD-502 m (Konica-Minolta, Tokyo, Japan).

\subsection{Estimation of Proline Content}

Proline (Pro) content was estimated by the method of Bates et al. [28]. Leaf was extracted by sulfosalicylic acid (3\%) and glacial acetic acid, acid ninhydrin, and then the mixture was heated at the boiling water bath at $100{ }^{\circ} \mathrm{C}$ for $60 \mathrm{~min}$. The reaction was terminated by placing the tube in an ice bath for $15 \mathrm{~min}$. Toluene was then used as reaction reagents with the previous mixture. Upper toluene chromophore was used for spectrophotometric observation at $520 \mathrm{~nm}$. The content of proline was calculated in the test sample using a standard curve.

\subsection{Determination of Electrolyte Leakage}

Electrolyte leakage (EL) was determined following the method of Dionisio-Sese and Tobita [29]. Electrical conductivity (EC) was measured by using a portable EC meter (Eutech Instruments, Singapore). Initial $\left(\mathrm{EC}_{1}\right)$ and final $\left(\mathrm{EC}_{2}\right) \mathrm{EC}$ were recorded, and $\mathrm{EL}$ was determined by the following formula: $\mathrm{EL}(\%)=\left(\mathrm{EC}_{1} / \mathrm{EC}_{2}\right) \times 100$.

\subsection{Measurement of Lipid Peroxidation}

The level of lipid peroxidation was measured by estimating malondialdehyde (MDA), a decomposition product of the per-oxidized polyunsaturated fatty acid composition of the membrane lipid, using 2-thiobarbituric acid (TBA) as the reactive material following the method of Heath and Packer [30]. The tissue was homogenized with ice-cold trichloroacetic acid (TCA) and then was centrifuged at $11,500 \times g$ at $4{ }^{\circ} \mathrm{C}$. The supernatant was mixed with a reaction mixture of thiobarbituric acid (TBA) and TCA and heated in a water bath. Then the cooled supernatant mixture was read at $532 \mathrm{~nm}$. The concentration of MDA was calculated by using the extinction coefficient of $155 \mathrm{mM}^{-1} \mathrm{~cm}^{-1}$ and was expressed as nmol of $\mathrm{MDA} \mathrm{g}^{-1} \mathrm{FW}$. 


\subsection{Measurement of Hydrogen Peroxide Generation}

The amount of $\mathrm{H}_{2} \mathrm{O}_{2}$ generated was recorded using the method described by Yu et al. [31]. Fresh leaf samples of $0.5 \mathrm{~g}$ were extracted with $3 \mathrm{~mL}$ of potassium phosphate (K-P) buffer (50 mM, pH 6.5) and centrifuged at $11,500 \times g$ for $15 \mathrm{~min}$ to obtain a clear supernatant. A total of $2 \mathrm{~mL}$ of this supernatant was mixed with $666.4 \mu \mathrm{L}$ of the reaction mixture $\left(5.5 \mathrm{mM} \mathrm{TiCl}_{4}\right.$ in $20 \% \mathrm{H}_{2} \mathrm{SO}_{4}$ ), incubated for $10 \mathrm{~min}$ at room temperature and centrifuged again at $11,500 \times g$ for $12 \mathrm{~min}$. To determine the $\mathrm{H}_{2} \mathrm{O}_{2}$ content, the absorption of the final supernatant was read at $410 \mathrm{~nm}$ with a spectrophotometer using $0.28 \mu \mathrm{M}^{-1} \mathrm{~cm}^{-1}$ as the extinction coefficient, and the results are expressed as nmol g ${ }^{-1} \mathrm{FW}$.

\subsection{Measurement of Antioxidant Enzyme Activities}

Leaf samples were homogenized using potassium-phosphate (K-P) buffer ( $\mathrm{pH} 7.0)$, AsA, $\beta$-mercaptoethanol, $\mathrm{KCl}$, and glycerol as an extraction buffer. After centrifuging, leaf extracts were used to determine protein and enzyme activity. Soluble protein concentration was measured using Coomassie brilliant blue dye following the technique of Bradford [32]. The optical absorbance was then recorded at $595 \mathrm{~nm}$, and a standard curve prepared by using bovine serum albumin was used for calculation.

Ascorbate peroxidase (EC: 1.11.1.11) activity was assayed following Nakano and Asada [33] by using K-P buffer ( $\mathrm{pH} 7.0$ ), AsA, ethylenediaminetetraacetic acid (EDTA), and $\mathrm{H}_{2} \mathrm{O}_{2}$ and absorbance were recorded at $290 \mathrm{~nm}$. APX activity was calculated with an extinction co-efficient $2.8 \mathrm{mM}^{-1} \mathrm{~cm}^{-1}$.

The activity of MDHAR (EC: 1.6.5.4) was measured by using a buffer solution containing ascorbate oxidase ( $\mathrm{AO})$, Tris- $\mathrm{HCl}$ buffer ( $\mathrm{pH} 7.5)$, AsA, and nicotinamide adenine dinucleotide phosphate (NADPH) according to the method described by Parvin et al. [34]. Optical absorbance was observed at $340 \mathrm{~nm}$. An extinction coefficient of $6.2 \mathrm{mM}^{-1} \mathrm{~cm}^{-1}$ was used for calculating its activity.

Dehydroascorbate reductase (EC: 1.8 .5 .1 ) activity was assayed according to Nakano and Asada [33] by using dehydroascorbate (DHA), K-P buffer (pH 7.0), GSH, and EDTA and absorbance were recorded at $265 \mathrm{~nm}$ and extinction coefficient $14 \mathrm{mM}^{-1} \mathrm{~cm}^{-1}$ was considered for calculating DHAR activity.

Catalase (EC: 1.11.1.6) activity was determined by using K-P buffer ( $\mathrm{pH} 7.0)$ and $\mathrm{H}_{2} \mathrm{O}_{2}$ according to the method described by Hasanuzzaman et al. [35]. Optical absorbance was recorded at $240 \mathrm{~nm}$ and calculated using $39.4 \mathrm{M}^{-1} \mathrm{~cm}^{-1}$ as the extinction coefficient.

Peroxidase (EC: 1.11.1.7) activity was estimated by using K-P buffer ( $\mathrm{pH} 7)$, catechol, and $\mathrm{H}_{2} \mathrm{O}_{2}$ according to the method described by Gong et al. [36]. Absorbance was recorded at $470 \mathrm{~nm}$ and expressed as $\mathrm{Umin}^{-1} \mathrm{mg}^{-1}$ protein.

Glutathione $S$-transferase (EC: 2.5.1.18) activity was assayed by using 1-chloro-2,4dinitrobenzene (CDNB), Tris-HCl buffer ( $\mathrm{pH}$ 6.5), and $\mathrm{GSH}$ according to the technique described by Rahman et al. [28] and absorbance was measured at $340 \mathrm{~nm}$.

\subsection{Measurement of Ion Contents}

The contents of $\mathrm{Na}^{+}, \mathrm{K}^{+}$and $\mathrm{Ca}^{2+}$ were measured from the dry shoot and root tissues by following Rahman et al. [37]. From ground homogenous dry plant samples, $100 \mathrm{mg}$ was digested with the acid mixture $\left(\mathrm{HNO}_{3}: \mathrm{HClO}_{4} ; 5: 1\right)$. Digestion of the sample was done at $70{ }^{\circ} \mathrm{C}$ for $48 \mathrm{~h}$. The $\mathrm{Na}^{+}, \mathrm{K}^{+}$and $\mathrm{Ca}^{2+}$ contents were determined from the digested solution by using the different lamps for the different minerals of atomic absorption spectrophotometer (AA-7000, Shimadzu, Japan), and the content was calculated using the standard curve of the respective mineral.

\subsection{Statistical Analysis}

Data accumulated from different parameters were subjected to analysis using CoStat v.6.400 [38] and one-way analysis of variance (ANOVA). For finding out mean differences among the replications, Tukey's honest significant difference (HSD) test at the 5\% level of significance was applied. 


\section{Results}

\subsection{Root and Shoot Length}

Both root and shoot growth were significantly inhibited with the increase in $\mathrm{NaCl}$ concentration from $1.5 \%$ to $3 \%$. Root length decreased by $8 \%$ of the control in response to $1.5 \%$ salt but was decreased by $25 \%$ by exposure to $3.0 \% \mathrm{NaCl}$ (Figure $1 \mathrm{~A}$ ). Shoot length showed a similar pattern of reduction to increasing salt stress (Figure 1B). The inclusion of SNP in the salt medium somewhat alleviated the negative effect of salt stress, as indicated by an increase in root length of 14 and $22 \%$, and an increase in shoot length of 8 and $11 \%$, in plants growing in $1.5 \%$ and $3 \% \mathrm{NaCl}$, respectively (Figure 1A,B). The beneficial role of SNP was further established by treatment with $\mathrm{Hb}$ and L-NAME, as scavenging $\mathrm{NO}$ or inhibiting its production in plants under salt stress further exacerbated the decreases in root and shoot length, compared to the plants treated with salt alone (Figure 1A,B).

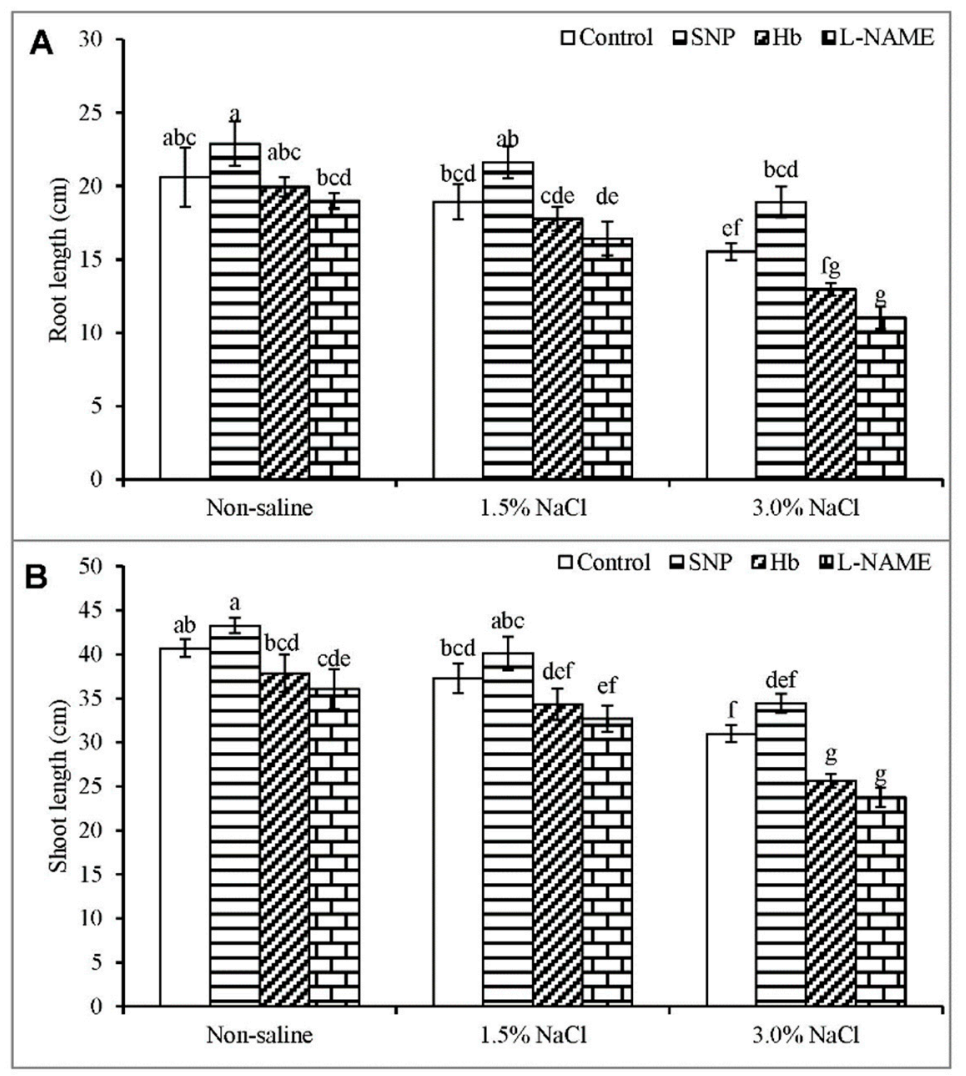

Figure 1. Root length (A) and shoot length (B) of Kandelia obovata treated with different salt concentrations and with $100 \mu \mathrm{M}$ sodium nitroprusside (SNP, a NO donor), hemoglobin (Hb, a NO scavenger), or N $\omega$-nitro- L-arginine methyl ester (L-NAME, a NO synthase inhibitor). Mean ( \pm SD) was calculated from three replicates for each treatment. Bars with different letters are significantly different at $p \leq 0.05$, applying Tukey's HSD test.

\subsection{Endogenous Nitric Oxide Level}

Treatment with SNP increased the NO content in nonstressed plants compared to the untreated control. Salt stress at $1.5 \%$ and $3 \%$ increased the NO content by 48 and $61 \%$, respectively, in the roots (Figure 2A) and by 8 and 12\%, respectively, in the leaf (Figure 2B), compared to the control treatment. Treatment of plants with SNP increased the NO content by $15 \%$ and $25 \%$ in the root (Figure $2 \mathrm{~A}$ ) and by $39 \%$ and $37 \%$ in the leaf (Figure $2 \mathrm{~B}$ ) in plants growing in 1.5 and $3 \% \mathrm{NaCl}$ respectively, compared to salt stress alone. Treatment of salt-stressed plants with either $\mathrm{Hb}$ or L-NAME decreased the NO level drastically, both the root and the shoot, confirming the inhibitory effect of $\mathrm{Hb}$ or L-NAME on NO levels. 


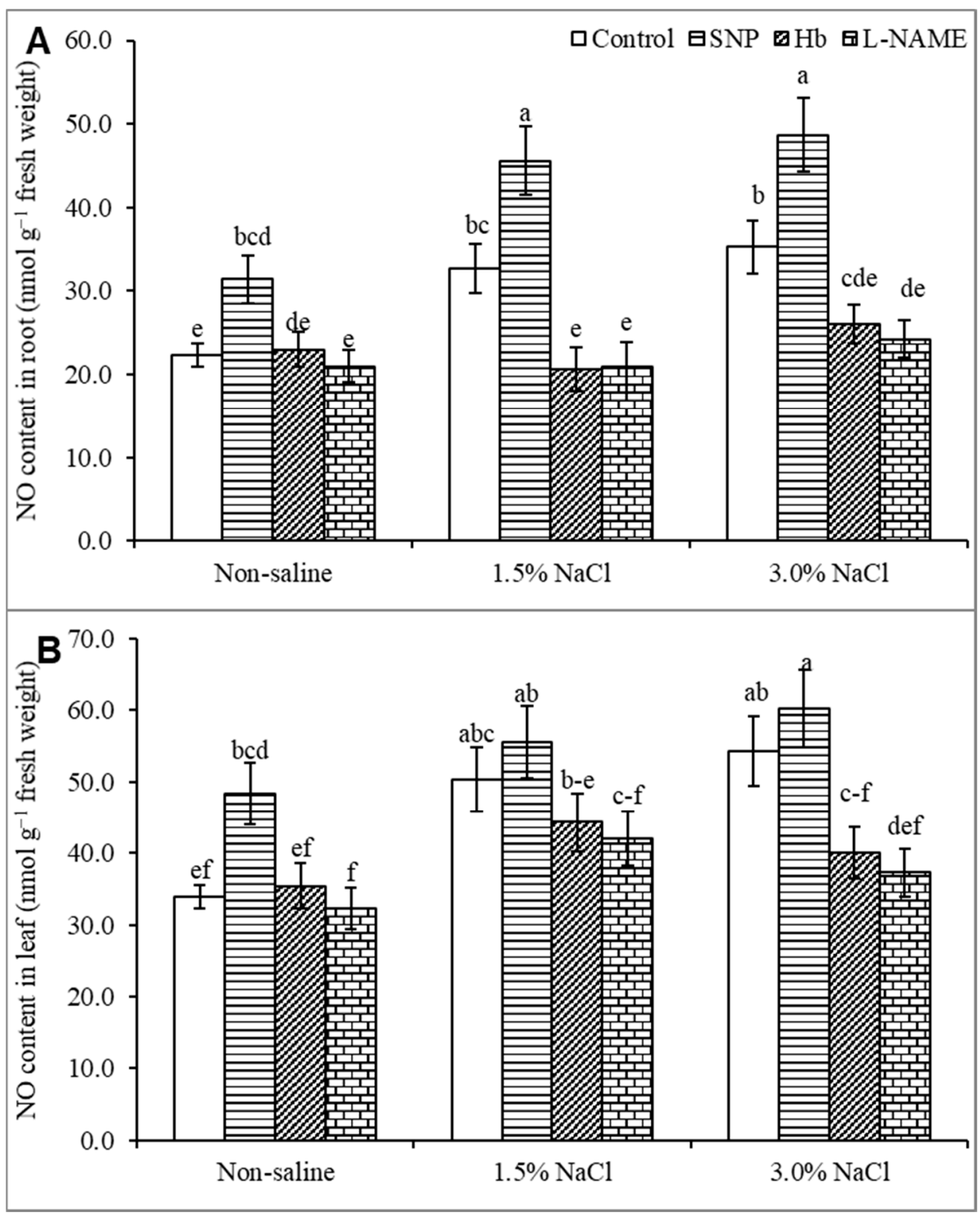

Figure 2. Endogenous NO content of Kandelia obovata root (A) and leaf (B) treated with different salt concentrations and with $100 \mu \mathrm{M}$ sodium nitroprusside (SNP, a NO donor), hemoglobin (Hb, a NO scavenger), or Nw-nitro- L-arginine methyl ester (L-NAME, a NO synthase inhibitor). Mean ( \pm SD) was calculated from three replicates for each treatment. Bars with different letters are significantly different at $p \leq 0.05$, applying Tukey's HSD test.

\subsection{Gas Exchange and Photosynthetic Parameters}

Various photosynthetic parameters were affected by salt exposure. Stomatal conductance $\left(\mathrm{g}_{\mathrm{s}}\right)$ did not change under the mild $1.5 \%$ salt stress but was substantially reduced by $3 \% \mathrm{NaCl}$ stress than the unstressed control (Figure 3A). Treatment of the salt-stressed plants with SNP increased $\mathrm{g}_{\mathrm{s}}$, even in the plants treated with $1.5 \% \mathrm{NaCl}$ (Figure 3A). Salt stress did not alter the $C_{i}$ value at $1.5 \% \mathrm{NaCl}$, but the $C_{i}$ value was decreased severely, by $50 \%$, in the $3 \%$ salt treatment compared to the unstressed control. Treatment of the salt-stressed plants with SNP had no significant effect on the $C_{i}$ level than salt stress alone. However, treatment with $\mathrm{Hb}$ or L-NAME decreased the $C_{i}$ value drastically (Figure 3B). The SPAD value also decreased in response to $3 \% \mathrm{NaCl}$ compared to the unstressed control. The SPAD value increased when salt-treated plants were treated with SNP, compared to plants exposed to salt stress alone. Treatment of salt-stressed plants with $\mathrm{Hb}$ or L-NAME substantially decreased 
the SPAD value (Figure 3C). As shown in Figure $3 \mathrm{D}$, the $\mathrm{P}_{n}$ was not affected significantly at $1.5 \% \mathrm{NaCl}$, but it was decreased by $24 \%$ under $3 \% \mathrm{NaCl}$ stress compared to the unstressed control. Treatment of the salt-stressed plants with SNP somewhat alleviated the detrimental effects of salt stress, resulting in increased $\mathrm{P}_{n}$ compared to the untreated salt-stressed plants. Treatment with $\mathrm{Hb}$ or L-NAME further decreased the $\mathrm{P}_{n}$ value compared to salt stress alone, supporting a positive effect of $\mathrm{NO}$ on photosynthesis (Figure 3D).

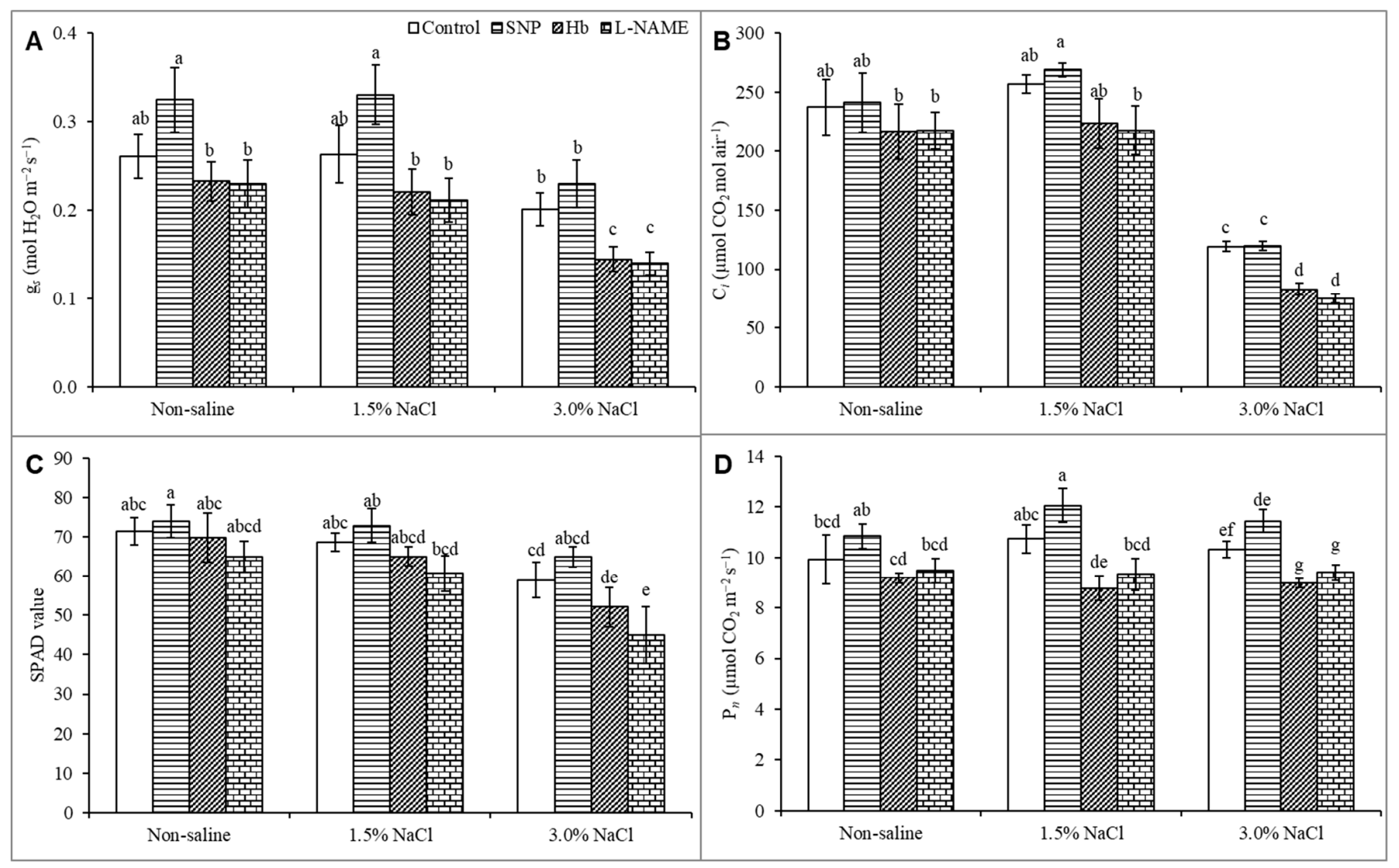

Figure 3. Stomatal conductance, $\mathrm{g}_{s}(\mathbf{A})$; internal $\left[\mathrm{CO}_{2}\right], \mathrm{C}_{i}(\mathbf{B})$; SPAD value $(\mathbf{C})$ and net photosynthesis, $\mathrm{P}_{n}(\mathbf{D})$ of Kandelia obovata treated with different salt concentrations and with $100 \mu \mathrm{M}$ sodium nitroprusside (SNP, a NO donor), hemoglobin (Hb, a NO scavenger), or N $\omega$-nitro- L-arginine methyl ester (L-NAME, a NO synthase inhibitor). Mean ( \pm SD) was calculated from three replicates for each treatment. Bars with different letters are significantly different at $p \leq 0.05$, applying Tukey's HSD test.

\subsection{Transpiration Rate and Water Use Efficiency}

The $\mathrm{T}_{r}$ value was unaffected by treatment with $1.5 \% \mathrm{NaCl}$ but was decreased by $20 \%$ in response to $3 \% \mathrm{NaCl}$ stress compared to the unstressed control (Figure $4 \mathrm{~A}$ ). Treatment of salt-stressed plants with SNP did not significantly increase the $\mathrm{T}_{r}$ value above that seen with salt stress alone. Treatment of salt-stressed plants with $\mathrm{Hb}$ or L-NAME further decreased $\mathrm{T}_{r}$ (Figure 4A). The WUE value did not change under salt stress than the unstressed control, and treatment with SNP did not significantly increase WUE (Figure 4B). However, treatment with $\mathrm{Hb}$ or L-NAME substantially decreased WUE, indicating a role for NO (Figure 4B). 


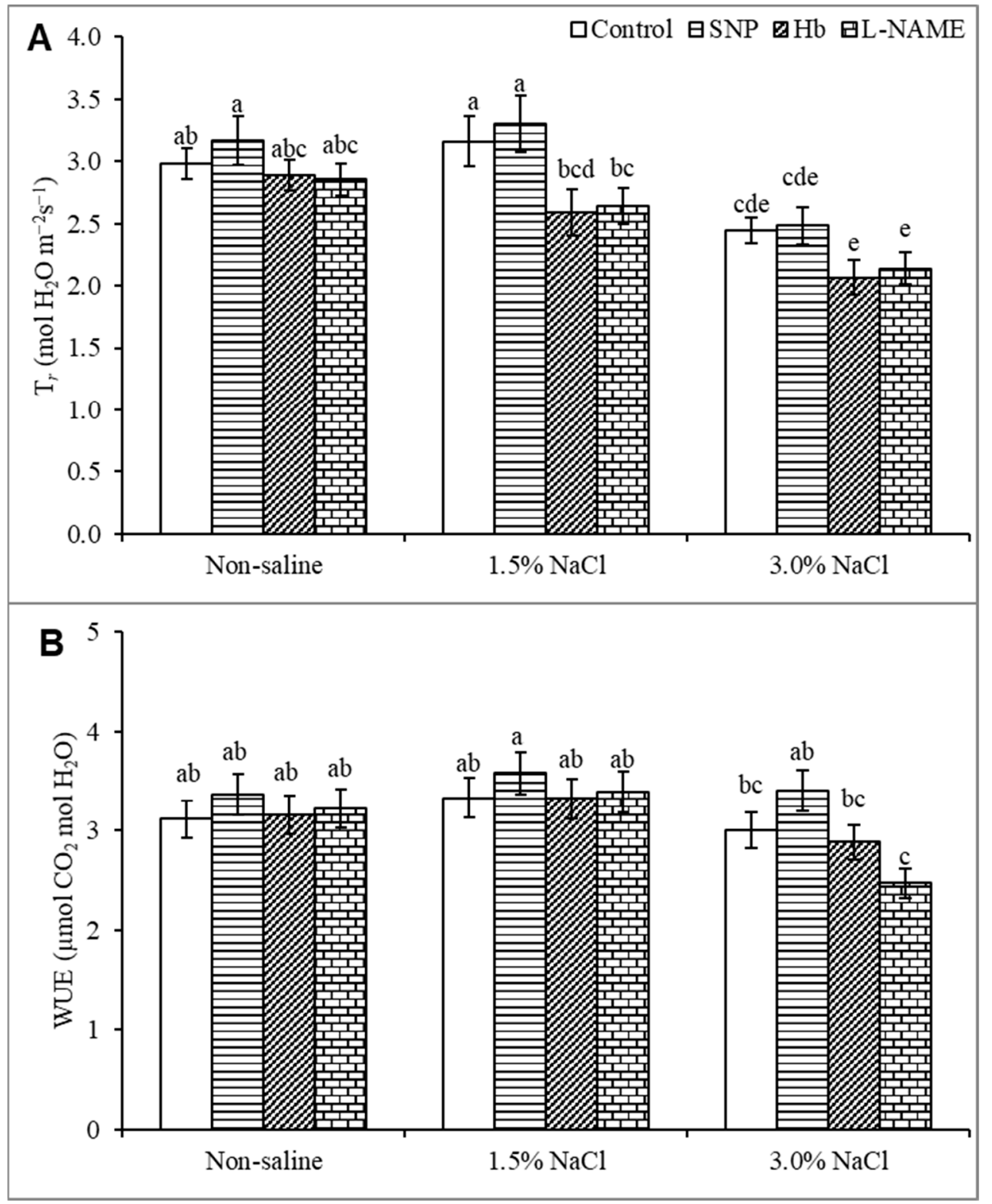

Figure 4. Transpiration rate (A) and water use efficiency, WUE (B) of Kandelia obovata treated with different salt concentrations and with $100 \mu \mathrm{M}$ sodium nitroprusside (SNP, a NO donor), hemoglobin ( $\mathrm{Hb}$, a NO scavenger), or N $\omega$-nitro- L-arginine methyl ester (L-NAME, a NO synthase inhibitor). Mean $( \pm S D)$ was calculated from three replicates for each treatment. Bars with different letters are significantly different at $p \leq 0.05$, applying Tukey's HSD test.

\subsection{Proline Content and Electrolyte Leakage}

The plant Pro content increased progressively with the increase in salt concentration. Compared to the control treatment, the Pro level increased by 66 and 197\% in the leaf and by $104 \%$ and $217 \%$ in the root in response to 1.5 and $3 \% \mathrm{NaCl}$, respectively. Treatment of salt-stressed plants with SNP further increased the Pro content, whereas treatment with $\mathrm{Hb}$ or L-NAME decreased the Pro content in both the root and shoot (Figure 5A,B). Salt stress caused electrolyte leakage (EL) from the root and leaf, with EL levels increasing by $49 \%$ and $111 \%$ from the leaf and $33 \%$ and $60 \%$ from the root in response to $1.5 \%$ and $3 \% \mathrm{NaCl}$, respectively compared to the unstressed control. Treatment with SNP decreased EL from the salt-stressed plants., whereas treatment with $\mathrm{Hb}$ or L-NAME increased EL (Figure 5C,D). 


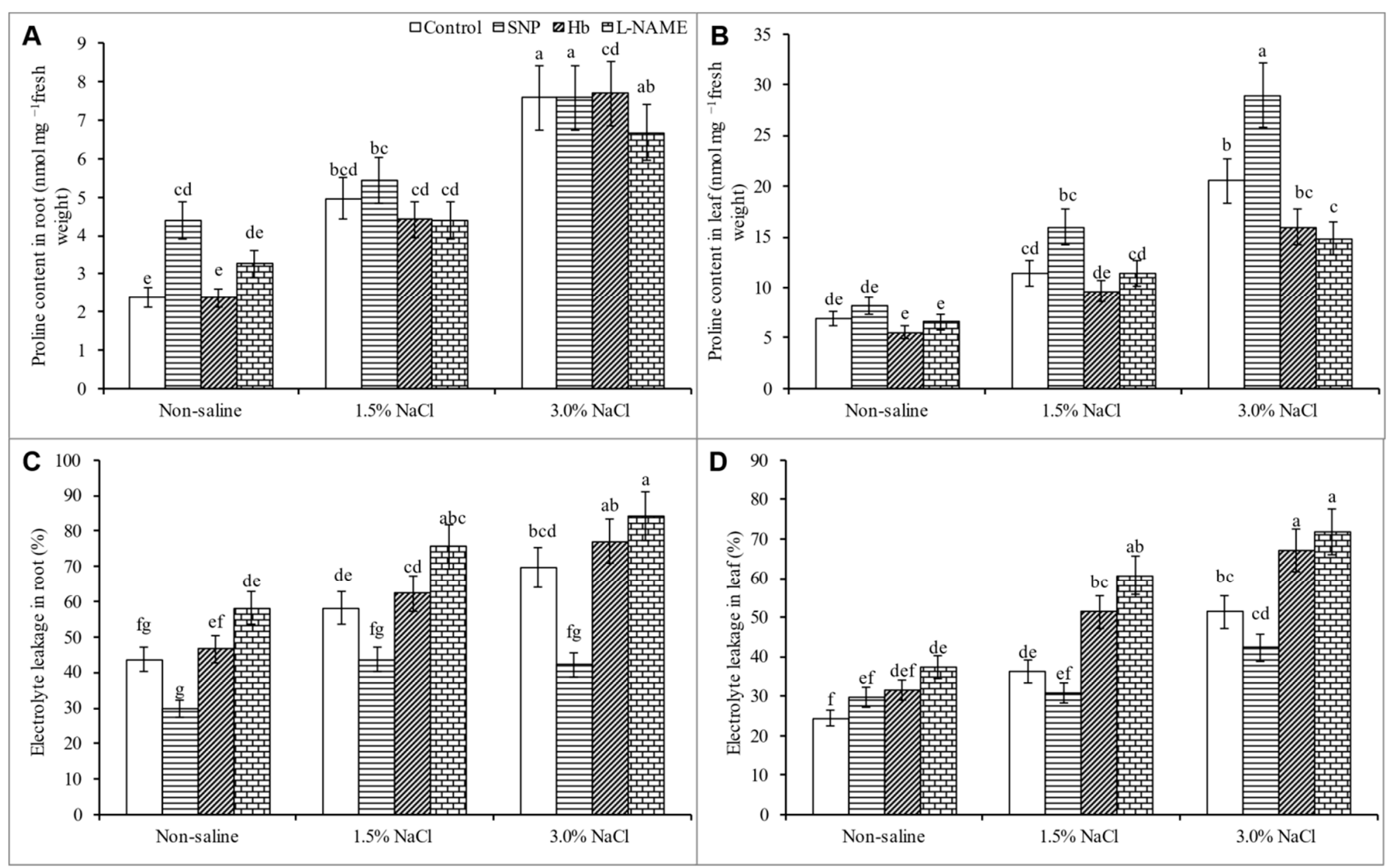

Figure 5. Proline content (A,B) and electrolyte leakage (C,D) in roots and leaves of Kandelia obovata treated with different salt concentrations and with $100 \mu \mathrm{M}$ sodium nitroprusside (SNP, a NO donor), hemoglobin (Hb, a NO scavenger), or N $\omega$-nitroL-arginine methyl ester (L-NAME, a NO synthase inhibitor). Mean ( \pm SD) was calculated from three replicates for each treatment. Bars with different letters are significantly different at $p \leq 0.05$, applying Tukey's HSD test.

\subsection{Oxidative Stress Markers}

The higher 3\% NaCl level increased the MDA levels in both the leaf and root by $97 \%$ and $60 \%$, respectively, compared to the unstressed control, whereas the lower $1.5 \%$ salt stress caused no significant change in MDA levels compared to the untreated control. Treatment with SNP decreased the MDA level in seedlings growing in $3 \% \mathrm{NaCl}$, whereas treatment with $\mathrm{Hb}$ or L-NAME caused increases in MDA levels in the salt-treated plants (Figure 6A,B). The hydrogen peroxide $\left(\mathrm{H}_{2} \mathrm{O}_{2}\right)$ content was not significantly increased in the leaf or root in response to $1.5 \% \mathrm{NaCl}$ stress and only showed a slight increase in response to $3 \%$ salt. Treatment of salt-stressed plants with SNP decreased the $\mathrm{H}_{2} \mathrm{O}_{2}$ levels compared to salt stress alone. Treatment of salt-stressed plants with $\mathrm{Hb}$ or L-NAME further increased the $\mathrm{H}_{2} \mathrm{O}_{2}$ levels above those observed in the SNP-treated salt-stressed plants (Figure 6C,D). 


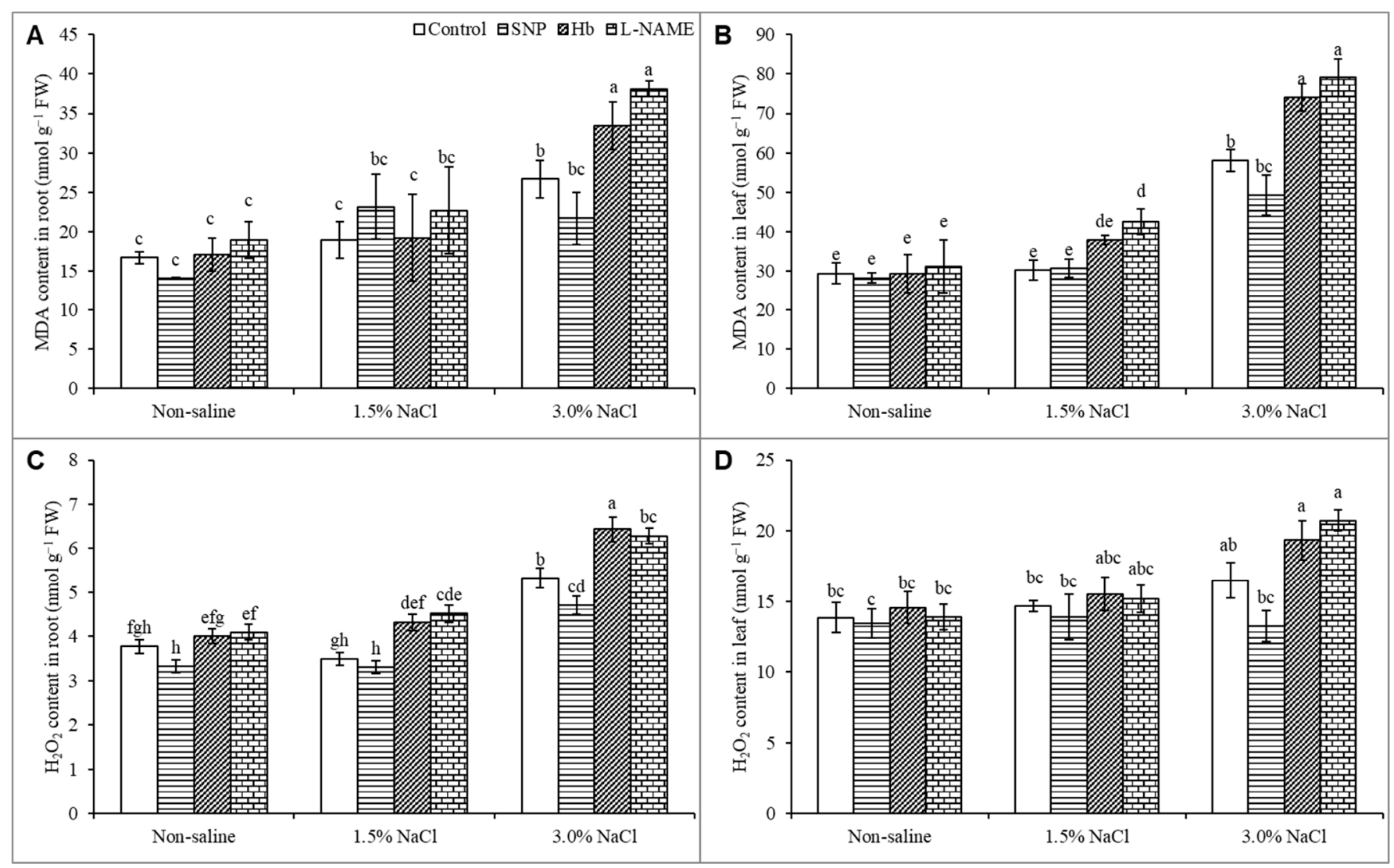

Figure 6. MDA content (A,B) and $\mathrm{H}_{2} \mathrm{O}_{2}$ content $(\mathbf{C}, \mathbf{D})$ in roots and leaves of Kandelia obovata treated with different salt concentrations and with $100 \mu \mathrm{M}$ sodium nitroprusside (SNP, a NO donor), hemoglobin (Hb, a NO scavenger), or N $\omega$-nitroL-arginine methyl ester (L-NAME, a NO synthase inhibitor). Mean ( \pm SD) was calculated from three replicates for each treatment. Bars with different letters are significantly different at $p \leq 0.05$, applying Tukey's HSD test.

\subsection{Activities of Antioxidant Enzymes}

In general, antioxidant enzyme activities (CAT, APX, MDHAR, and DHAR) increased in response to salt stress compared to the unstressed control. The exceptions were leaf and root DHAR activity in response to $1.5 \% \mathrm{NaCl}$ stress and leaf MDHAR in response to both levels of salt stress. Treatment with SNP did not cause significant increases in enzyme activity in salt-treated plants, except for the leaf DHAR activity in the $3 \% \mathrm{NaCl}$ treatment (Figure 7A-F). 


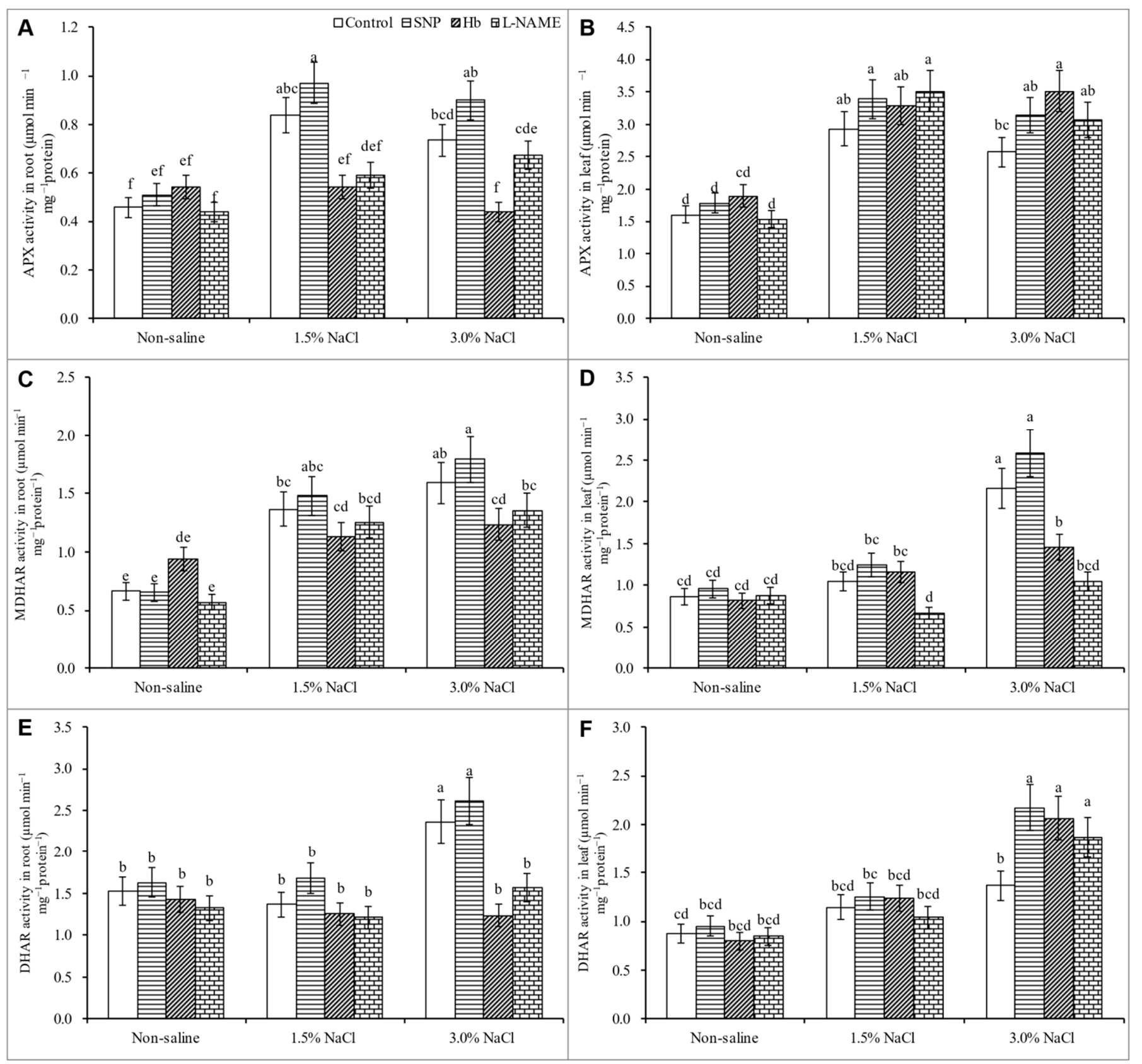

Figure 7. Activity of $\operatorname{APX}(\mathbf{A}, \mathbf{B}), \operatorname{MDHAR}(\mathbf{C}, \mathbf{D})$ and $\operatorname{DHAR}(\mathbf{E}, \mathbf{F})$ in roots and leaves of Kandelia obovata treated with different salt concentrations and with $100 \mu \mathrm{M}$ sodium nitroprusside (SNP, a NO donor), hemoglobin (Hb, a NO scavenger), or N $\omega$-nitro- L-arginine methyl ester (L-NAME, a NO synthase inhibitor). Mean ( $\pm \mathrm{SD}$ ) was calculated from three replicates for each treatment. Bars with different letters are significantly different at $p \leq 0.05$, applying Tukey's HSD test.

The POD activity increased by 118 and $74 \%$ in the root and by $117 \%$ and $34 \%$ in the leaf in response to 1.5 and $3 \% \mathrm{NaCl}$ treatment, respectively, compared to the unstressed control (Figure 8A,B). The activity of CAT increased only in response to $1.5 \% \mathrm{NaCl}$ stress, compared to the unstressed control (Figure $8 \mathrm{~B}, \mathrm{C}$ ). No changes were noted in root and leaf GST activity under salt stress compared to the unstressed control (Figure 8E,F). Treatment with SNP increased the CAT activity in the leaf and root above that observed in plants exposed to salt stress alone (Figure $8 \mathrm{~A}-\mathrm{F}$ ). 


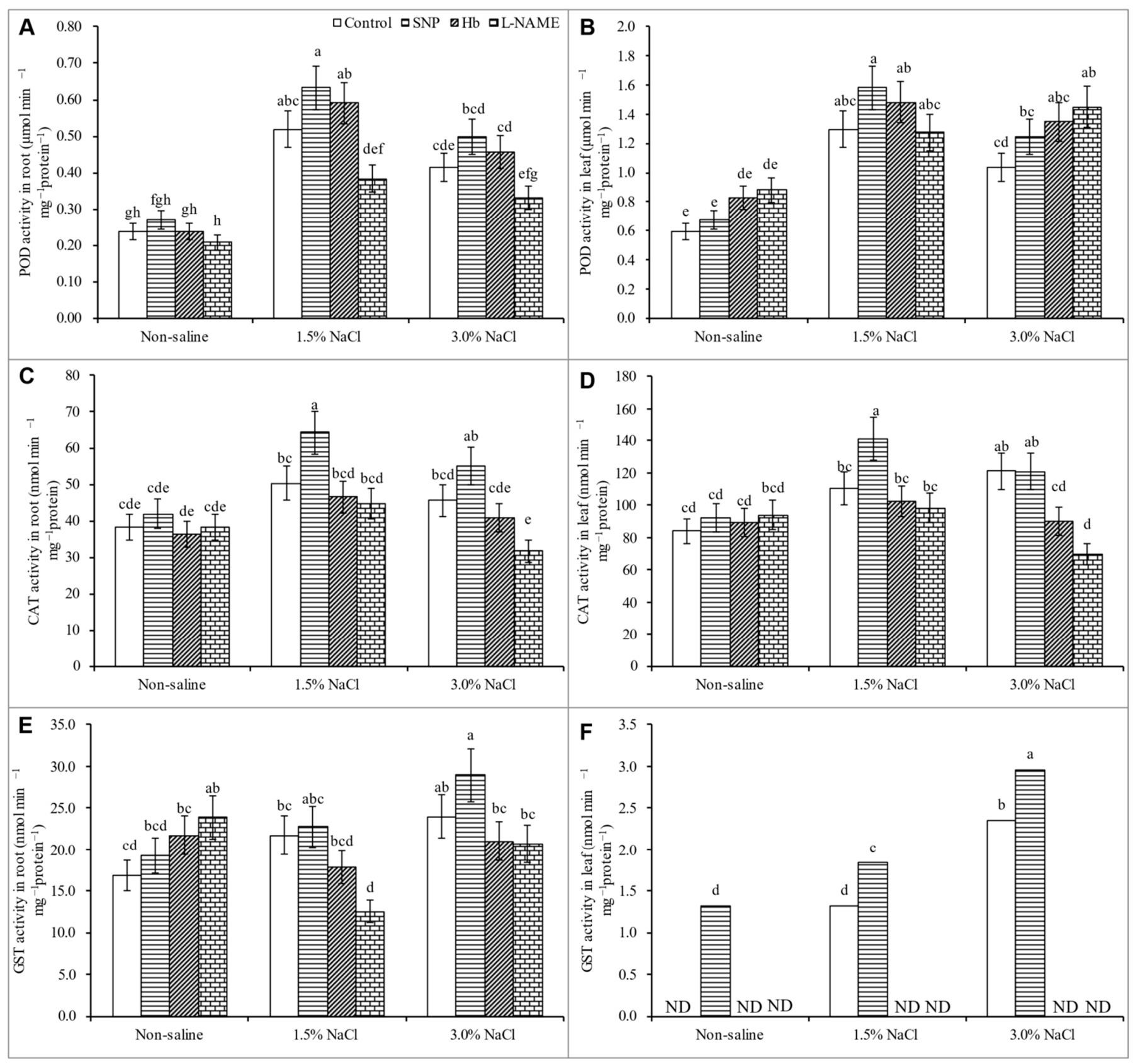

Figure 8. Activity of POD (A,B), CAT (C,D) and GST (E,F) in roots and leaves of Kandelia obovata treated with different salt concentrations and with $100 \mu \mathrm{M}$ sodium nitroprusside (SNP, a NO donor), hemoglobin (Hb, a NO scavenger), or Nw-nitroL-arginine methyl ester (L-NAME, a NO synthase inhibitor). Mean $( \pm S D)$ was calculated from three replicates for each treatment. Bars with different letters are significantly different at $p \leq 0.05$, applying Tukey's HSD test.

\subsection{Ion Contents}

Salt stress created ion toxicity by increasing the plant $\mathrm{Na}^{+}$content, decreasing the $\mathrm{K}^{+}$content, and disrupting the $\mathrm{Na}^{+} / \mathrm{K}^{+}$balance; however, it also disrupted nutrient homeostasis. Treatment of plants with $1.5 \% \mathrm{NaCl}$ increased the $\mathrm{Na}^{+}$levels in the leaf and root by $317 \%$ and $738 \%$, respectively, while treatment with $3 \% \mathrm{NaCl}$ increased these levels by $725 \%$ and $465 \%$, respectively compared to the unstressed control (Figure $9 \mathrm{~A}, \mathrm{~B}$ ). By contrast, the $\mathrm{K}^{+}$content in the leaf and root decreased by $23 \%$ and $14 \%$, respectively, at $1.5 \% \mathrm{NaCl}$ stress, and by $45 \%$ and $41 \%$, respectively, at $3 \% \mathrm{NaCl}$ compared to the unstressed control (Figure $9 \mathrm{C}, \mathrm{D}$ ). Consequently, the $\mathrm{K}^{+} / \mathrm{Na}^{+}$ratio decreased considerably in both the leaf and the root (Figure 9E,F). 


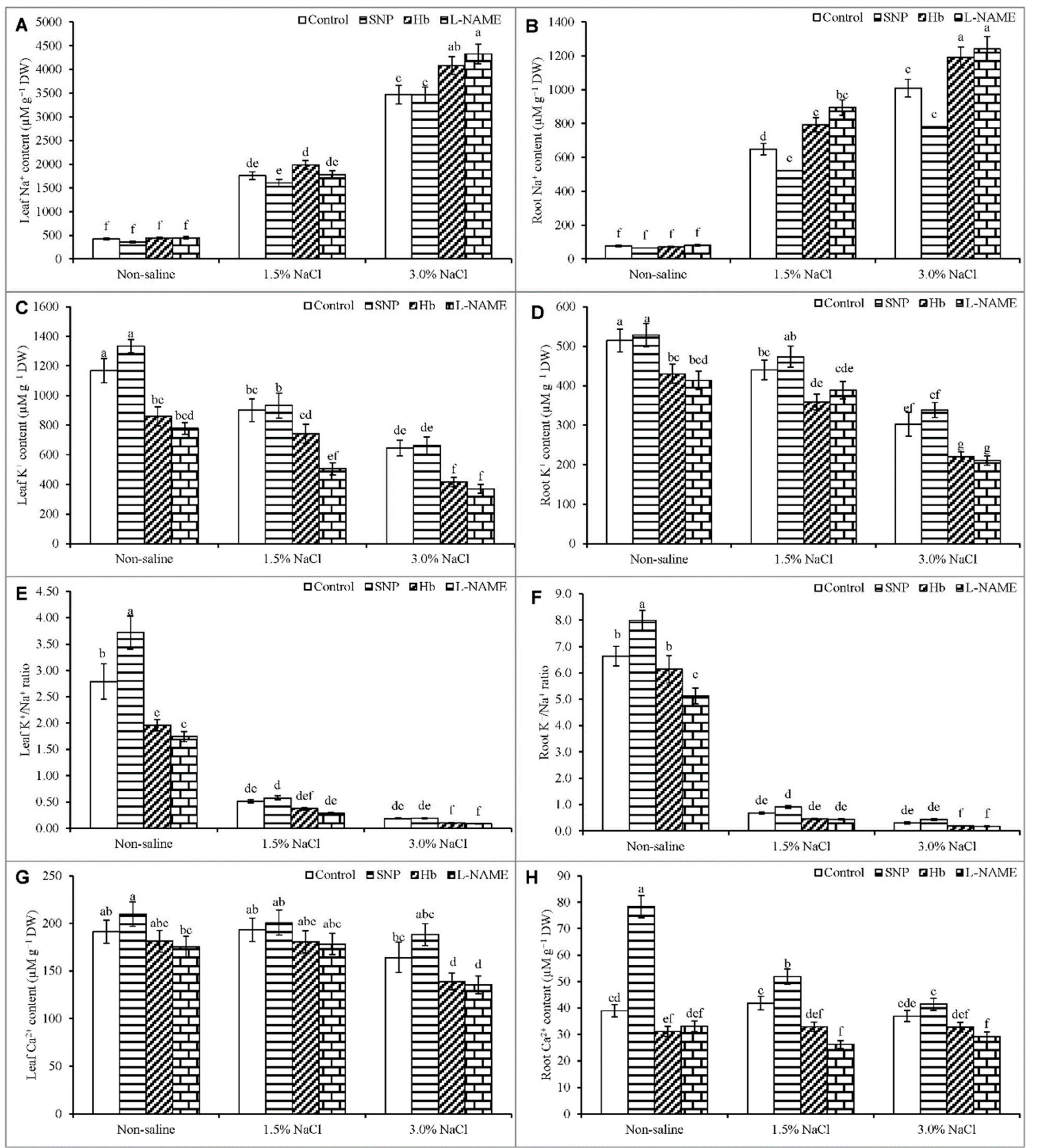

Figure 9. $\mathrm{Na}^{+}(\mathbf{A}, \mathbf{B}), \mathrm{K}^{+}(\mathbf{C}, \mathbf{D}), \mathrm{K}^{+} / \mathrm{Na}^{+}$ratio $(\mathbf{E}, \mathbf{F})$ and $\mathrm{Ca}^{2+}$ content in roots $(\mathbf{G})$ and leaves $(\mathbf{H})$ of Kandelia obovata treated with different salt concentrations and with $100 \mu \mathrm{M}$ sodium nitroprusside (SNP, a NO donor), hemoglobin (Hb, a NO scavenger), or N $\omega$-nitro- L-arginine methyl ester (L-NAME, a NO synthase inhibitor). Mean ( \pm SD) was calculated from three replicates for each treatment. Bars with different letters are significantly different at $p \leq 0.05$, applying Tukey's HSD test. 
The content of $\mathrm{Ca}^{2+}$ decreased in response to $3 \% \mathrm{NaCl}$ stress, whereas the root $\mathrm{Ca}^{2+}$ was not significantly affected compared to the unstressed control (Figure 9G,H). Treatment of salt-stressed plants with SNP decreased the $\mathrm{Na}^{+}$content, increased the $\mathrm{K}^{+}$content, and improved the $\mathrm{K}^{+} / \mathrm{Na}^{+}$ratio in both the root and the leaf, compared to the plants treated with salt stress alone. The treatment with SNP also improved the $\mathrm{Ca}^{2+}$ level under salt stress, compared to salt treatment alone. Treatment with $\mathrm{Hb}$ or L-NAME caused further decreases in the $\mathrm{Ca}^{2+}$ level than the salt-stressed plants treated with SNP (Figure 9A-H).

\section{Discussion}

In this study, we investigated how the supplementation and inhibition of NO regulates the physiology of K. obovate. In salt-affected K. obovata plants, the endogenous NO level also increased, as reported in previous studies that have examined plants growing in stressful environments $[39,40]$. This rise in NO is suggested to play a signaling function in response to stress [16]. Treatment of salt-stressed K. obovata seedlings with SNP further increased the endogenous NO level, indicating an efficient uptake and accumulation of NO donated from SNP, in agreement with a similar role documented for SNP in previous studies [41,42]. By contrast, treatment with $\mathrm{Hb}$ and L-NAME decreased the $\mathrm{NO}$ levels both under normal and salt stress conditions, indicating the efficacy of these agents in scavenging NO or inhibiting its biosynthesis.

Kandelia obovata plants subjected to salt stress showed a significant decrease in shoot and root growth, which is due to the disruption of plant water relations that occurred from osmotic stress imposed by the salinity. Moreover, ion toxicity aggravates the stress response upon entry of the salt into the plant cells, which triggers secondary damage to the cell [43]. In the present study, NO supplementation via SNP treatment appeared to reinstate the plant growth suppressed by salt stress, while $\mathrm{NO}$ removal by scavenging with $\mathrm{Hb}$ or suppression of NO production with L-NAME prevented this restoration and worsened the effects of salt stress in K. obovata plants. A similar effect of $\mathrm{NO}$ on the restoration of plant growth under salt stress also has been demonstrated by other researchers [25,40,44-47].

In this study, $K$. obovata showed substantial changes in several gas exchange and photosynthetic parameters, namely $P_{n}, g_{s}, T_{r}, C_{i}$, and WUE, especially when exposed to 3\% $\mathrm{NaCl}$. Salt stress creates a physiological drought through the generation of osmotic stress. This physiological drought can cause stomatal closure, thereby reducing photosynthetic $\mathrm{CO}_{2}$ assimilation. In the halophyte $K$. obovata, a high salt stress level caused a decrease in $g_{s}$ and a subsequent marked decrease in $C_{i}$. As facultative halophyte, $K$. obovata plant was able to tolerate $1.5 \%$ salt and did not show any changes in $\mathrm{P}_{n}$ under that level of stress; however, its $\mathrm{P}_{n}$ value decreased in response to growth in 3\% salt compared to the unstressed control. Several reasons may explain this response. In the present study, $g_{s}, T_{r}$, $C_{i}$, and WUE decreased at the higher level of salt stress. Reductions in $g_{s}$ and $C_{i}$ under high salt stress are the direct reasons for the observed decrease in $P_{n}$. The salinity-induced decline in $P_{n}$ was positively related to the reduction in $g_{s}$ and $C_{i}$, as reported previously in soybean plants [48].

Treatment with $\mathrm{Hb}$ and L-NAME reversed the positive effects of SNP in the absence of salt stress. In K. obovata plants, the negative effects on the SPAD value, $P_{n}, g_{s}, T_{r}, C_{i}$, and WUE were more prominent following treatment with the NO inhibitors. Treatment of the salt-treated plants with $\mathrm{Hb}$ and L-NAME caused a further decrease in SPAD value, $P_{n}$, $g_{s}, T_{r}, C_{i}$, and WUE than was observed with salt stress alone. These inhibitors hindered $\mathrm{NO}$ accumulation in two ways, by scavenging and by suppressing the NO biosynthesis that would be produced by plants under salt stress. Inhibition of uptake and accumulation of NO from exogenous sources like SNP would also be suppressed.

Plants facing osmotic stress accumulate osmolytes inside the cells to correct their water balance. The large increase in Pro, which increased gradually with the rise in salt level, indicates that $K$. obovata can cope with salt-induced osmotic stress. This capacity was further increased by SNP treatment, as indicated by the further increase in Pro content. Proline is widely known for its osmoprotective effects, as well as its proficiency at scavenging 
hydroxyl radicals and stabilizing the structure and function of macromolecules, including DNA, protein, and membranes [48-50]. Proline protects the photosynthetic machinery and thus enhances photosynthesis. It acts as an energy storage material during salt stress, thereby improving survival and adaptation $[45,51]$. Treatment of salt-stressed K. obovata plants with SNP increased the Pro level, thereby improving osmoregulation, ROS scavenging, and the stabilization of biomembranes and biomolecules. In the present study, exogenous SNP promoted an increase in the Pro level in salt-affected plants, as previously reported for Pro levels in cadmium-stressed mung bean [52]. The decrease in Pro following $\mathrm{Hb}$ and L-NAME treatments that decreased $\mathrm{NO}$ availability also abruptly decreased the Pro level, indicating a potential role for SNP in regulating Pro levels.

Salinity is similar to all other abiotic stresses in that it causes oxidative stress, and saltinduced oxidative stress has been reported in different plant species $[4,53]$. The resulting oxidative damage is a consequence of altered photosystem activity and stomatal movement, ion toxicity, disrupted nutrient homeostasis and disturbed antioxidant defense mechanisms in the salt-affected plants $[44,54,55]$. In our study, salt-induced oxidative damage was observed in K. obovata plants, with the more severe damage noted at the higher salt level. The high levels of $\mathrm{H}_{2} \mathrm{O}_{2}$ measured in this plant confirmed a salt-induced ROS overproduction. The high MDA levels are the result of membrane lipid peroxidation due to salt-induced oxidative damage. Some reports support similar findings in other plants under salt stress $[44,54]$.

In the present study, SNP decreased the levels of $\mathrm{H}_{2} \mathrm{O}_{2}$ and MDA in the salt-affected plants. Previous studies on mung bean have shown that SNP treatment can induce inhibition of lipoxygenase (LOX) activity and reduce oxidative stress [52]. Nitric oxide can react with $\mathrm{O}_{2}{ }^{\bullet-}$ to form peroxynitrite $\left(\mathrm{ONOO}^{-}\right)$, which can then be detoxified by peroxiredoxins [56]. Treatment with SNP reduced the production of $\mathrm{H}_{2} \mathrm{O}_{2}$ and $\mathrm{O}_{2}{ }^{\bullet-}$ and led to a reduction in MDA accumulation in ryegrass under copper toxicity stress [19]. Nitric oxide lessens oxidative damage in several ways, through reduction of $\mathrm{O}_{2}{ }^{\bullet-}$ and subsequent oxidative stress, through inhibition of LOX activity, and through NO-induced regulation of molecules like Pro, which also scavenge ROS and stabilize biomembranes and biomolecules.

The results from $\mathrm{Hb}$ and L-NAME treatments in the present study confirm that oxidative damage was exacerbated to an even greater extent by these NO modifiers to even higher levels than were observed by salt stress alone. Treatment of salt-stressed plants with $\mathrm{Hb}$ and L-NAME promoted the production of $\mathrm{H}_{2} \mathrm{O}_{2}$, raised MDA levels, and increased electrolyte leakage above the levels seen in the salt-stressed, SNP-treated plants. This result confirmed that $\mathrm{Hb}$ and L-NAME reduced $\mathrm{NO}$ levels, thereby promoting greater oxidative damage.

In the present study, both leaf $\mathrm{Na}^{+}$and root $\mathrm{Na}^{+}$contents were strongly increased to levels expected to create ion toxicity $[18,57]$. The increased $\mathrm{Na}^{+}$levels decreased $\mathrm{K}^{+}$ levels, and decreased $\mathrm{K}^{+} / \mathrm{Na}^{+}$ratios in both the leaf and root indicate a condition of disrupted and imbalanced ion homeostasis. These cations directly compete with each other to enter the plants under salt stress and represents a common sign of salt-induced ion toxicity, as demonstrated in several previous studies $[44,46,58]$. The leaf and root $\mathrm{Ca}^{2+}$ contents also decreased similarly to the $\mathrm{K}^{+}$contents, in agreement with the findings of other studies [44,46]. Treatment of salt-stressed plants with NO in the form of SNP resulted in a decreased root and leaf $\mathrm{Na}^{+}$content, an increased $\mathrm{K}^{+}$content, an increased $\mathrm{K}^{+} / \mathrm{Na}^{+}$ratio, and an increased $\mathrm{Ca}^{2+}$ content, compared to salt stress alone. The NO provided by SNP promoted cell membrane reconstruction and restored the ability to exclude toxic ions and to take up nutrient elements necessary for plant development [44]. Treatment of cotton plants with SNP upregulated the expression of vital salt-tolerant genes, including the plasma membrane $\mathrm{Na}^{+} / \mathrm{H}^{+}$antiporter (SOS1) and the vacuolar $\mathrm{Na}^{+} / \mathrm{H}^{+}$ antiporter (NHX1), allowing salt-stressed plants to decrease $\mathrm{Na}^{+}$uptake from the salt solution, while simultaneously promoting an increased $\mathrm{K}^{+}$uptake [46]. Several other 
studies have also shown an SNP-induced reduction of $\mathrm{Na}^{+}$uptake and augmentation of $\mathrm{K}^{+}$ uptake, with an eventual increase in the $\mathrm{K}^{+} / \mathrm{Na}^{+}$ratio [44,58].

Some evidence also supports our findings regarding SNP-induced improvement in nutrient uptake. For example, the concentrations of minerals in the leaves and roots of salt-affected wheat plants were enhanced by treatment with SNP [18]. Improved $\mathrm{K}^{+}$levels in salt-affected cotton were also demonstrated in response to SNP treatment $[44,58-60]$. In the present study, K. obovata plants treated with $\mathrm{Hb}$ and L-NAME showed reduced endogenous NO levels under salt stress but higher levels of $\mathrm{Na}^{+}$, lower levels of $\mathrm{K}^{+}$and $\mathrm{Ca}^{2+}$ and a reduced $\mathrm{K}^{+} / \mathrm{Na}^{+}$ratio in both roots and leaves. These results indicate that $\mathrm{Hb}$ and L-NAME removed $\mathrm{NO}$ and inhibited its accumulation, thereby promoting the development of ion toxicity and disruption of mineral homeostasis that was even more severe than were observed under the salt-stress condition. $\mathrm{Hb}$ and L-NAME inhibited the endogenous production of $\mathrm{NO}$ in salt-affected plants and also eliminated the beneficial effect of exogenous SNP in salt-stressed K. obovata plants.

Nitric oxide enhances the transformation of $\mathrm{O}_{2}{ }^{\bullet-}$ to $\mathrm{H}_{2} \mathrm{O}_{2}$ and $\mathrm{O}_{2}$ through enhanced activities of SOD; the $\mathrm{H}_{2} \mathrm{O}_{2}$ is then detoxified by the $\mathrm{H}_{2} \mathrm{O}_{2}$ scavenging enzymes APX, GPX, and GST [59]. The activities of the enzymes MDHAR and DHAR, which are AsA recycling enzymes, were increased by treatment with SNP. Therefore, SNP treatment most likely increased the levels of AsA, allowing greater scavenging of ROS. Treatment with SNP was reported to increase GR's activity, which increased the GSH content by enhancing its recycling process, and this increased GSH also participated in ROS detoxification processes [21,59]. Treatment with SNP improved the activities of SOD, POD, and CAT in wheat plants subjected to salt stress [44], in agreement with the present findings regarding antioxidant defense systems, ROS detoxification, and oxidative stress alleviation by SNP. Treatment of salt-stressed plants with $\mathrm{Hb}$ or L-NAME reversed these responses, leading to a reduction in antioxidant enzyme activities and an enhancement of oxidative stress. These findings further confirm a role for $\mathrm{NO}$ in enhancing the antioxidant defense system and oxidative stress tolerance.

\section{Conclusions}

The facultative mangrove plant, K. obovata, showed the least damage under low-level salt stress $(1.5 \%)$. This low stress did not change the studied physiological attributes significantly, thereby confirming the salt tolerance of this plant species. At the higher level of salt stress $(3 \%)$, the plants showed oxidative damage. When the salt-affected plants were treated with SNP, the endogenous NO level increased, and the plants showed significant improvements in most of the studied physiological attributes compared to salt-treated control plants. The effect of NO was further confirmed by reducing the NO levels in salt-stressed plants with the NO scavenger $\mathrm{Hb}$ and the NO biosynthesis inhibitor L-NAME. The use of these NO modulators exacerbated the adverse effects of salt stress, providing strong evidence for a role for $\mathrm{NO}$ in improving salt adaptation and tolerance traits in the $K$. obovata plant.

Author Contributions: Conceptualization, M.H., M.F. and H.O.; methodology, M.H., M.I., M.F. and K.N.; formal analysis, M.H. and K.N.; investigation, M.H. and M.I.; resources, H.O. and M.F.; data curation, M.H.; writing-original draft preparation, M.H. and K.N.; writing-review and editing, M.H. and M.I.; visualization, M.H.; supervision, H.O.; All authors have read and agreed to the published version of the manuscript.

Funding: This research was funded by the Japan Society for the Promotion of Science (JSPS).

Institutional Review Board Statement: Not applicable.

Informed Consent Statement: Not applicable.

Data Availability Statement: Not applicable. 
Acknowledgments: We acknowledge Shin Watanabe for providing the propagules and the portable photosynthesis meter. We also thank Yoshinobu Kawamitsu for helping in measuring gas exchange parameters and photosynthesis.

Conflicts of Interest: The authors declare no conflict of interest.

\section{References}

1. Pitman, M.G.; Läuchli, A. Global impact of salinity and agricultural ecosystems. In Salinity: Environment-Plants-Molecules; Läuchli, A., Lüttge, U., Eds.; Kluwer: Dordrecht, The Netherlands, 2002; pp. 3-20.

2. Chen, Y.P.; Ye, Y. Growth and physiological responses of saplings of two mangrove species to intertidal elevation. Mar. Ecol. Prog. Ser. 2013, 482, 107-118. [CrossRef]

3. Hasanuzzaman, M.; Nahar, K.; Fujita, M. Plant response to salt stress and role of exogenous protectants to mitigate salt-induced damages. In Ecophysiology and Responses of Plants under Salt Stress; Ahmad, P., Azooz, M., Prasad, M., Eds.; Springer: New York, NY, USA, 2013; pp. 25-87.

4. Kawana, Y.; Sasamoto, H.; Ashihara, H. Mechanism of salt tolerance in mangrove plants. Bull. Soc. Sea Water Sci. 2008, 62, 207-214.

5. Ali, A.; Yun, D.J. Salt stress tolerance; what do we learn from halophytes? J. Plant Biol. 2017, 60, 431-439. [CrossRef]

6. Jiang, G.-F.; Goodale, U.M.; Liu, Y.-Y.; Hao, G.-Y.; Cao, K.-F. Salt management strategy defines the stem and leaf hydraulic characteristics of six mangrove tree species. Tree Physiol. 2017, 37, 389-401. [CrossRef]

7. Zheng, C.; Tang, J.; Chen, J.; Liu, W.; Qiu, J.; Peng, X.; Ye, Y. Mechanisms on inhibition of photosynthesis in Kandelia obovata due to extreme cold events under climate change. Ecol. Process. 2016, 5, 20. [CrossRef]

8. Liu, J.; Shi, D.C. Photosynthesis, chlorophyll fluorescence, inorganic ion and organic acid accumulations of sunflower in responses to salt and salt-alkaline mixed stress. Photosynthetica 2010, 48, 127-134. [CrossRef]

9. Naeem, M.S.; Jin, Z.L.; Wan, G.L.; Liu, D.; Liu, H.B.; Yoneyama, K.; Zhou, W.J. 5-Aminolevulinic acid improves photosynthetic gas exchange capacity and ion uptake under salinity stress in oilseed rape (Brassica napus L.). Plant Soil. 2010, 332, 405-415. [CrossRef]

10. Wu, X.X.; Ding, H.D.; Zhu, Z.W.; Yang, S.J.; Zha, D.S. Effects of 24-epibrassinolide on photosynthesis of eggplant (Solanum melongena L.) seedlings under salt stress. Afr. J. Biotechnol. 2012, 11, 8665-8671.

11. Ahmad, P.; Sharma, S. Salt stress and phyto-biochemical responses of plants. Plant Soil Environ. 2008, 54, 89-99.

12. Ahmad, P.; Nabi, G.; Ashraf, M. Cadmium-induced oxidative damage in mustard. [Brassica juncea (L.) Czern. \& Coss.] plants can be alleviated by salicylic acid. S. Afr. J. Bot. 2011, 77, 36-44.

13. Hasanuzzaman, M.; Bhuyan, M.H.M.B.; Zulfiqar, F.; Raza, A.; Mohsin, S.M.; Mahmud, J.A.; Fujita, M.; Fotopoulos, V. Reactive oxygen species and antioxidant defense in plants under abiotic stress: Revisiting the crucial role of a universal defense regulator. Antioxidants 2020, 9, 681. [CrossRef]

14. Hasanuzzaman, M.; Bhuyan, M.H.M.B.; Parvin, K.; Bhuiyan, T.F.; Anee, T.I.; Nahar, K.; Hossen, M.S.; Zulfiqar, F.; Alam, M.M.; Fujita, M. Regulation of ROS metabolism in plants under environmental stress: A review of recent experimental evidence. Int. J. Mol. Sci. 2020, 21, 8695. [CrossRef] [PubMed]

15. Sachdev, S.; Ansari, S.A.; Ansari, M.I.; Fujita, M.; Hasanuzzaman, M. Abiotic stress and reactive oxygen species: Generation, signaling and defense mechanisms. Antioxidants 2021, 10, 277. [CrossRef] [PubMed]

16. Molassiotis, A.; Tanou, G.; Diamantidis, G. NO says more than 'YES' to salt tolerance Salt priming and systemic nitric oxide signaling in plants. Plant Signal. Behav. 2010, 5, 209-212. [CrossRef] [PubMed]

17. Beligni, M.V.; Lamattina, L. Nitric oxide interferes with plant photooxidative stress by detoxifying reactive oxygen species. Plant Cell Environ. 2002, 25, 737-740. [CrossRef]

18. Chen, J.; Xiong, D.-Y.; Wang, W.-H.; Hu, W.-J.; Simon, M.; Xiao, Q.; Chen, J.; Liu, T.-W.; Liu, X.; Zheng, H.L. Nitric oxide mediates root $\mathrm{K}^{+} / \mathrm{Na}^{+}$balance in a mangrove plant, Kandelia obovata, by enhancing the expression of AKT1-Type $\mathrm{K}^{+}$channel and $\mathrm{Na}^{+} / \mathrm{H}^{+}$ antiporter under high salinity. PLoS ONE 2013, 8, e71543. [CrossRef]

19. Dong, Y.; Xu, L.; Wang, Q.; Fan, Z.; Kong, J.; Bai, X. Effects of exogenous nitric oxide on photosynthesis, antioxidative ability, and mineral element contents of perennial ryegrass under copper stress. J. Plant Interact. 2014, 9, 402-411. [CrossRef]

20. Fatma, M.; Khan, N.A. Nitric oxide protects photosynthetic capacity inhibition by salinity in Indian mustard. J. Funct. Environ. Bot. 2014, 4, 106-116. [CrossRef]

21. Nahar, K.; Hasanuzzaman, M.; Alam, M.M.; Rahman, A.; Suzuki, T.; Fujita, M. Polyamine and nitric oxide crosstalk: Antagonistic effects on cadmium toxicity in mung bean plants through upregulating the metal detoxification, antioxidant defense and methylglyoxal detoxification systems. Ecotoxicol. Environ. Saf. 2016, 126, 245-255. [CrossRef]

22. Monreal, J.A.; Arias-Baldrich, C.; Pérez-Montaño, F.; Gandullo, J.; Echevarría, C.; García-Mauriño, S. Factors involved in the rise of phosphoenolpyruvate carboxylase-kinase activity caused by salinity in sorghum leaves. Planta 2013, 237, 1401-1413. [CrossRef] [PubMed]

23. Tan, J.; Zhao, H.; Hong, J.; Han, Y.; Li, H.; Zhao, W. Effects of exogenous nitric oxide on photosynthesis, antioxidant capacity and proline accumulation in wheat seedlings subjected to osmotic stress. World J. Agric. Sci. 2008, 4, 307-313.

24. Wu, X.X.; Zhu, X.H.; Chen, J.L.; Yang, S.J.; Ding, H.D.; Zha, D.S. Nitric oxide alleviates adverse salt-induced effects by improving the photosynthetic performance and increasing the antioxidant capacity of eggplant (Solanum melongena L.). J. Hortic. Sci. Biotechnol. 2013, 88, 352-360. [CrossRef] 
25. Fatma, M.; Masood, A.; Per, T.S.; Khan, N.A. Nitric oxide alleviates salt stress inhibited photosynthetic performance by interacting with sulfur assimilation in mustard. Front. Plant Sci. 2016, 7, 521. [CrossRef]

26. Fatma, M.; Masood, A.; Per, T.S.; Rasheed, F.; Khan, N.A. Interplay between nitric oxide and sulfur assimilation in salt tolerance in plants. Crop J. 2016, 4, 153-161. [CrossRef]

27. Ali, Q.M.; Ashraf, M.; Humera, H. Ameliorating effect of foliar applied proline on nutrient uptake in water stressed maize (Zea mays L.) plants. Pak. J. Bot. 2008, 40, 211-219.

28. Bates, L.S.; Waldren, R.P.; Teare, I.D. Rapid determination of free proline for water stress studies. Plant Soil 1973, 39, $205-207$. [CrossRef]

29. Dionisio-Sese, M.L.; Tobita, S. Antioxidant responses of rice seedlings to salinity stress. Plant Sci. 1998, 135, 1-9. [CrossRef]

30. Heath, R.L.; Packer, L. Photoperoxidation in isolated chloroplast. I. Kinetics and stoichiometry of fatty acid peroxidation. Arch. Biochem. Biophy. 1968, 125, 189-198. [CrossRef]

31. Yu, C.W.; Murphy, T.M.; Lin, C.H. Hydrogen peroxide induced chilling tolerance in mung beans mediated through ABAindependent glutathione accumulation. Funct. Plant Biol. 2003, 30, 955-963. [CrossRef] [PubMed]

32. Bradford, M.M. A rapid and sensitive method for the quantitation of microgram quantities of protein utilizing the principle of protein-dye binding. Anal. Biochem. 1976, 72, 248-254. [CrossRef]

33. Nakano, Y.; Asada, K. Hydrogen peroxide is scavenged by ascorbate-specific peroxidase in spinach chloroplasts. Plant Cell Physiol. 1981, 22, 867-880.

34. Parvin, K.; Nahar, K.; Hasanuzzaman, M.; Bhuyan, M.H.M.B.; Mohsin, S.M.; Fujita, M. Exogenous vanillic acid enhances salt tolerance of tomato: Insight into plant antioxidant defense and glyoxalase systems. Plant Physiol. Biochem. 2020, 150, 109-120. [CrossRef] [PubMed]

35. Hasanuzzaman, M.; Alam, M.M.; Nahar, K.; Mohsin, S.M.; Bhuyan, M.H.M.B.; Parvin, K.; Hawrylak-Nowak, B.; Fujita, M. Silicon-induced antioxidant defense and methylglyoxal detoxification works coordinately in alleviating nickel toxicity in Oryza sativa L. Ecotoxicology 2019, 28, 261-276. [CrossRef]

36. Gong, H.; Zhu, X.; Chen, 1.; Wang, S.; Zhang, C. Silicon alleviates oxidative damage of wheat plants in pots under drought. Plant Sci. 2005, 169, 313-321. [CrossRef]

37. Rahman, A.; Nahar, K.; Hasanuzzaman, M.; Fujita, M. Calcium supplementation improves $\mathrm{Na}^{+} / \mathrm{K}^{+}$ratio, antioxidant defense and glyoxalase systems in salt-stressed rice seedlings. Front. Plant Sci. 2016, 7, 609. [CrossRef]

38. CoStat. CoStat-Statistics Software Version 6.400; CoHort Software: Monterey, CA, USA, 2008.

39. Hasanuzzaman, M.; Hossain, M.A.; Fujita, M. Nitric oxide modulates antioxidant defense and methylglyoxal detoxification system and reduces salinity-induced damage in wheat seedling. Plant Biotechnol. Rep. 2011, 5, 353-365. [CrossRef]

40. Huang, J.; Zhu, C.; Hussain, S.; Huang, J.; Liang, Q.; Zhu, L.; Cao, X.; Kong, Y.; Li, Y.; Wang, L.; et al. Effects of nitric oxide on nitrogen metabolism and the salt resistance of rice (Oryza sativa L.) seedlings with different salt tolerances. Plant Physiol. Biochem. 2020, 155, 374-383. [CrossRef]

41. Groppa, M.D.; Rosales, E.P.; Iannone, M.F.; Benavides, M.P. Nitricoxide, polyamines and Cd-induced phytotoxicity in wheat roots. Phytochemistry 2008, 69, 2609-2615. [CrossRef] [PubMed]

42. Li, X.; Gong, B.; Xu, K. Interaction of nitric oxide and polyamines involves antioxidants and physiological strategies against chilling-induced oxidative damage in Zingiber officinale Roscoe. Sci. Hort. 2014, 170, 237-248. [CrossRef]

43. Deinlein, U.; Stephan, A.B.; Horie, T.; Luo, W.; Xu, G.; Schroeder, J.I. Plant salt-tolerance mechanisms. Trends Plant Sci. 2014, 19, 371-379. [CrossRef]

44. Tian, X.; He, M.; Wang, Z.; Zhang, J.; Song, Y.; He, Z.; Dong, Y. Application of nitric oxide and calcium nitrate enhances tolerance of wheat seedlings to salt stress. Plant Growth Regul. 2015, 77, 343-356. [CrossRef]

45. Reddy, P.S.; Jogeswar, G.; Rasineni, G.K.; Maheswari, M.; Reddy, A.R.; Varshney, R.K.; Kishor, P.B.K. Proline overaccumulation alleviates salt stress and protects photosynthetic and antioxidant enzyme activities in transgenic sorghum (Sorghum bicolor (L.) Moench). Plant Physiol. Biochem. 2015, 94, 104-113. [CrossRef]

46. Kong, X.; Wang, T.; Li, W.; Tang, W.; Zhang, D.; Dong, H. Exogenous nitric oxide delays salt-induced leaf senescence in cotton (Gossypium hirsutum L.). Acta Physiol. Plant. 2016, 38, 61. [CrossRef]

47. Li, X.; Pan, Y.; Chang, B.; Wang, Y.; Tang, Z. NO promotes seed germination and seedling growth under high salt may depend on EIN3 protein in Arabidopsis. Front. Plant Sci. 2016. [CrossRef]

48. Ahmad, P.; Jaleel, C.A.; Salem, M.A.; Nabi, G.; Sharma, S. Roles of enzymatic and non-enzymatic antioxidants in plants during abiotic stress. Crit. Rev. Biotechnol. 2010, 30, 161-175. [CrossRef] [PubMed]

49. Lu, K.X.; Cao, B.H.; Feng, X.P.; He, Y.; Jiang, D.A. Photosynthetic response of salt-tolerant and sensitive soybean varieties. Photosynthetica 2009, 47, 381-387. [CrossRef]

50. Khan, M.N.; Siddiqui, M.H.; Mohammad, F.; Naeem, M.; Khan, M.M.A. Calcium chloride and gibberellic acid protect linseed (Linum usitatissimum L.) from $\mathrm{NaCl}$ stress by inducing antioxidative defence system and osmoprotect ant accumulation. Acta Physiol. Plant. 2010, 32, 121-132. [CrossRef]

51. Jogaiah, S.; Govind, S.R.; Tran, L.S.P. Systems biology-based approaches toward understanding drought tolerance in food crops. Crit. Rev. Biotechnol. 2013, 33, 23-39. [CrossRef] [PubMed] 
52. Nahar, K.; Hasanuzzaman, M.; Rahman, A.; Alam, M.M.; Mahmud, J.A.; Suzuki, T.; Fujita, M. Polyamines confer salt tolerance in mung bean (Vigna radiata L.) by reducing sodium uptake, improving nutrient homeostasis, antioxidant defense, and methylglyoxal detoxification systems. Front. Plant Sci. 2016, 7, 1104. [CrossRef]

53. Hasanuzzaman, M.; Oku, H.; Nahar, K.; Bhuyan, M.H.M.B.; Mahmud, J.A.; Baluska, F.; Fujita, M. Nitric oxide-induced salt stress tolerance in plants: ROS metabolism, signaling, and molecular interactions. Plant Biotechnol. Rep. 2018, 12, 77-92. [CrossRef]

54. Shabala, S.; Munns, R. Salinity stress: Physiological constraints and adaptive mechanisms. In Plant Stress Physiology; Shabala, S., Ed.; CABI: Wallingford, UK, 2012; pp. 59-93.

55. Khan, M.I.R.; Iqbal, N.; Masood, A.; Per, T.S.; Khan, N.A. Salicylic acid alleviates adverse effects of heat stress on photosynthesis through changes in proline production and ethylene formation. Plant Signal. Behav. 2013, 8, e26374. [CrossRef]

56. Leitner, M.; Vandelle, E.; Gaupels, F.; Bellin, D.; Delledonne, M. NO signals in the haze: Nitric oxide signaling in plant defense. Curr. Opin. Plant Biol. 2009, 12, 451-458. [CrossRef] [PubMed]

57. Shabala, S. Learning from halophytes: Physiological basis and strategies to improve abiotic stress tolerance in crops. Ann. Bot. 2013, 112, 1209-1221. [CrossRef] [PubMed]

58. Munns, R.; Tester, M. Mechanisms of salinity tolerance. Annu. Rev. Plant Biol. 2008, 59, 651-681. [CrossRef] [PubMed]

59. Sheldon, A.R.; Dalal, R.C.; Kirchhof, G.; Kopittke, P.M.; Menzies, N.W. The effect of salinity on plant-available water. Plant Soil. 2017, 418, 477-491. [CrossRef]

60. Khan, M.N.; Siddiqui, M.H.; Mohammad, F.; Naeem, M. Interactive role of nitric oxide and calcium chloride in enhancing tolerance to salt stress. Nitric Oxide 2012, 27, 210-218. [CrossRef] [PubMed] 